Original Article

\title{
DEVELOPMENT AND VALIDATION OF NEW RP-UPLC METHOD FOR THE DETERMINATION OF CEFDINIR IN BULK AND DOSAGE FORM
}

\author{
KRISHNAPHANISRI PONNEKANTI, RAJA SUNDARARAJAN*
}

GITAM Institute of Pharmacy, GITAM University, Visakhapatnam-Andhra Pradesh, India 530045, GITAM Institute of Pharmacy, GITAM University, Gandhi Nagar, Rushikonda, Visakhapatnam 530045, Andhra Pradesh, India

Email: sraja61@gmail.com

Received: 23 Oct 2017 Revised and Accepted: 22 Nov 2017

\section{ABSTRACT}

Objective: The objective of the study was to develop and validate a new rapid and sensitive reverse phase ultra-performance liquid chromatographic (RP-UPLC) method for determination of cefdinir in bulk drug and dosage form.

Methods: Separation was achieved with an Acquity SB C18 $(100 \times 2 \mathrm{~mm}) 1.8 \mu \mathrm{m}$ column with an isocratic mobile phase containing a mixture of orthophosphoric acid and acetonitrile $(60: 40 \mathrm{v} / \mathrm{v})$ and $\mathrm{pH}$ adjusted to 2.8 . The flow rate of the mobile phase was $0.3 \mathrm{ml} / \mathrm{min}$ with a column temperature of $30^{\circ} \mathrm{C}$ and detection wavelength at $285 \mathrm{~nm}$.

Results: The method was validated with respect to linearity, accuracy, precision, detection limits, robustness and specificity. The precision of the results, stated as the relative standard deviation was below $1.5 \%$. The calibration curve was linear over a concentration range from 25 to $150 \mu \mathrm{g} / \mathrm{ml}$ with a correlation coefficient of 0.9993 . The accuracy of the method demonstrated at three levels in the range of $50 \%, 100 \%$ and $150 \%$ of the specification limit. The recovery of cefdinir was found to be in the range of 98 to $102 \%$, whereas the detection limits were found to be 0.17 and $0.51 \mu \mathrm{g} / \mathrm{ml}$. Forced degradation study was carried out under acidic, alkaline, oxidative, photolytic and thermal conditions to prove the stabilityindicating ability of the developed UPLC method.

Conclusion: The developed method was validated with respect to linearity, accuracy, precision limit of detection and quantification, robustness and specificity. The method was applied successfully for the determination of cefdinir in tablets.

Keywords: UPLC, Cefdinir, Method development, Validation

(C) 2018 The Authors. Published by Innovare Academic Sciences Pvt Ltd. This is an open access article under the CC BY license (http://creativecommons.org/licenses/by/4.0/) DOI: http://dx.doi.org/10.22159/ijpps.2018v10i1.23256

\section{INTRODUCTION}

Pharmaceutical analysis by definition deals with the analysis of drugs, pharmaceutical substances and raw materials. Drug analysis exposes identification, characterization and determination of the drugs in dosage forms and biological fluids etc. The international conference on harmonisation (ICH) guidelines attained a great deal in harmonizing the definitions of the impurities in new drug substances [1]. It is required to perform all the investigations on suitable reference standards of drug and impurities to acquire meaningful specifications. In order to meet the tasks to confirm the high degree of purity of drug substances and drug products, a system is proposed for profiling drug impurity. Lastly, analytical methods based on analytical instrumentation must be employed to quantitate drug substance and its impurities. Drug analysis is performed by various analytical methods like spectral methods, electroanalytical methods and chromatographic methods. HPLC has proven to be predominant technology used in laboratories worldwide during past 30 y [2, 3] High-performance liquid chromatography (HPLC) is one mode of chromatography, one of the utmost used analytical techniques. As HPLC methods have been commonly used for routine quality control assessment of drugs, because of its sensitivity, repeatability and specificity. However, HPLC is a well-known technique used in controlling the quality and consistency of active pharmaceutical ingredients (API 's) and dosage forms. It is often a slow technique because of the complexity of some of the samples and it could still be enhanced. A novel category of separation technique, ultraperformance liquid chromate-graphy (UPLC), has proven to be one of the most promising developments in the area of fast chromatographic separations with its unique characteristics of high chromatographic resolution, speed and sensitivity analysis [4]. UPLC provides the speed by using novel low micron particles that decreases chromatographic run times and also double peak capacity or resolution time [5]. UPLC uses 95 percent less solvent and significantly improves productivity in the laboratory. UPLC system reduces considerable time and cost per sample from the analytical process while improving the quality of results, the system allows chromatographers to work at higher efficiencies, flow rates and back pressures [6].

Cefdinir, chemically is [6R-[6 $\alpha, 7 \beta$ (Z)]]-7-[[(2-amino4-thiozolyl] (hydroxyimino) acetyl] amino]-3ethenyl-8-oxo-5-thia-1-azabicyclo (4.2.2)-Oct-2-one-2-carboxylic acid [7]. The empirical formula of cefdinir is $\mathrm{C}_{14} \mathrm{H}_{13} \mathrm{~N}_{5} \mathrm{O}_{5} \mathrm{~S}_{2}$ with a molecular weight of 395.42 [8] Cefdinir is a semisynthetic cephalosporin antibiotic. The drug is an oral aminothiazolyl hydroxyimino cephalosporin. It has a broad spectrum of activity, excellent therapeutic action against susceptible gram-positive and gram-negative bacteria as having potent antimicrobial activity, excellent efficacy, convenient dosing and favorable tolerability compared with other antimicrobial agents. Cefdinir shows its bactericidal action by inhibiting cell wall synthesis [9]. It is found to be constant in presence of some, but not all $\beta$ lactamase enzymes. As a result, many organisms resistant to penicillin's and some cephalosporin are susceptible to Cefdinir [9]. Entire survey of the literature of cefdinir exposed several methods for determination in pharmaceutical formulations and biological matrices like spectro-photometry [10], polarographic technique [11], HPLC [12] and LC/MS/MS methods [13]. However, maximum of these analytical methods do not appear to have general utility especially at the industrial level where simple, cost-effective and specific methods are needed [14]. There are very limited works that have been done on this drug by HPLC but no method has been stated by UPLC technique. Thus, the objective of work was to develop and validate a stability indicating RP-UPLC method for the determination of cefdinir in bulk drug and dosage forms

\section{MATERIALS AND METHODS}

Instruments

The chromatography analysis was performed using a Waters Acquity UPLC separation module (Waters Corporation, Milford, USA) 
equipped with an UV/visible detector, binary solvent manager and autosampler system. The output signal was checked and processed using Empower 2 software. The $\mathrm{pH}$ of the solutions was measured by a $\mathrm{pH}$ meter (Mettler-Toledo, Switzerland).

\section{Chemicals and reagents}

Spectrum Pharma Research Solutions (Hyderabad) supplied a sample of Cefdinir. Orthophosphoric acid and perchloric acids were purchased from RFCL, Rankeem Limited. HPLC grade water and acetonitrile were obtained from Rankem, Avantor Performance Material India Limited. High purity water was obtained by using Millipore Milli Q Plus water purification system.

\section{Chromatographic conditions}

The method was developed by using an Acquity SB C18 $(100 \times 2$ $\mathrm{mm}) 1.8 \mu \mathrm{m}$ column with an isocratic mobile phase containing a mixture of orthophosphoric acid and acetonitrile $(60: 40 \mathrm{v} / \mathrm{v})$. The $\mathrm{pH}$ was adjusted to 2.8 . The mobile phase was filtered through the $0.22 \mu$ filter under vacuum filtration. Flow rate of the mobile phase was $0.3 \mathrm{ml} / \mathrm{min}$. The column temperature was maintained at $30{ }^{\circ} \mathrm{C}$ and the eluted compounds were monitored at the wavelength of 285 $\mathrm{nm}$. The sample injection volume was $1 \mu \mathrm{l}$.

\section{Preparation of solutions}

\section{Preparation of diluents}

The diluent used for the analysis was prepared by using homogenous mixture of $500 \mathrm{ml}$ of water and $500 \mathrm{ml}$ acetonitrile.

\section{Preparation of mobile phase}

A mixture of orthophosphoric acid and acetonitrile in the ratio of $60: 40(\mathrm{v} / \mathrm{v})$ was prepared and the $\mathrm{pH}$ was adjusted to 2.8 with ortho-phosphoric acid. The mixture was filtered through $0.22 \mu$ membrane filter under vacuum filtration.

\section{Preparation of standard solution}

A $25 \mathrm{mg}$ of cefdinir was weighed on a calibrated analytical balance and transferred accurately into a $25 \mathrm{ml}$ clean and dry volumetric flask. It was further diluted to volume with 1:1 acetonitrile and water $(25 \mathrm{ml})$ to produce $25 \mu \mathrm{g} / \mathrm{ml}$ stock solution. This stock solution was diluted appropriately to prepare standard of the $100 \mu \mathrm{g} / \mathrm{ml}$.

\section{Preparation of sample solution}

The sample solution was prepared by taking 10 tablets of cefdinir which were weighed individually; their mean weight was determined and was ground to a fine powder using a glass mortar and pestle. An equivalent of $25 \mathrm{mg}$ of cefdinir was accurately weighed and transferred to a separate $25 \mathrm{ml}$ volumetric flask. The volume was adjusted with acetonitrile and water $(1: 1 \mathrm{v} / \mathrm{v})$ and the resultant solution was sonicated for $15 \mathrm{~min}$, filtered through a $0.22 \mu$ membrane filter under vacuum filtration.

\section{Validation procedure}

Method validation was achieved as per ICH guidelines for determination of the cefdinir [5]. The following validation features were addressed: linearity, detection limit, quantification limit, precision, accuracy, robustness and specificity.

\section{Linearity}

Standard solutions at six different concentration levels ranging from $25 \mu \mathrm{g} / \mathrm{ml}$ to $150 \mu \mathrm{g} / \mathrm{ml}$ were prepared and analyzed in order to demonstrate the linearity. The regression curve was obtained by plotting peak area versus concentration. The regression equation was obtained by using the least squares method [15].

\section{Limits of detection and quantification (LOD and LOQ)}

The sensitivity of the method was measured by calculating the limit of detection and limit of quantification. The LOD and LOQ were assessed at signals to noise ratio of 3:1 and 10:1 respectively by injecting a series of dilute solutions with known concentrations.

\section{Precision}

The Precision of the method was determined by injecting a standard solution of cefdinir for six times and measured the area for all six injections in UPLC chromatographic system.

\section{Accuracy}

The standard addition and recovery experiments were conducted to demonstrate the accuracy of the method. The accuracy of the method evaluated in triplicate at three concentration levels, i.e. $50 \%$, $100 \%$ and $150 \%$ of target test concentration and the percentages of recoveries were calculated.

\section{Robustness}

The robustness of a method was demonstrated by altering experimental conditions and chromatographic resolution to evaluate robustness. The deliberate changes were made in the chromategraphic conditions, viz. change in flow rate by $\pm 0.1 \mathrm{ml} / \mathrm{min}$ and change in the column temperature $\pm 5^{\circ} \mathrm{C}$.

\section{Specificity}

Forced degradation studies of cefdinir was carried out under conditions of acid hydrolysis (5N hydrochloric acid was added and refluxed for $30 \mathrm{~min}$ at $60^{\circ}$ ), base hydrolysis ( $5 \mathrm{~N}$ sodium hydroxide was added and refluxed for $30 \mathrm{~min}$ at $60^{\circ}$ ), peroxide treatment ( $20 \%$ hydrogen peroxide was kept for $30 \mathrm{~min}$ at $60^{\circ}$ ), thermal degradation (solid API was heated at $105^{\circ}$ for $6 \mathrm{~h}$ in an oven) and photolytic degradation (sample was exposed to UV for one day). The treated samples were diluted with diluent to the desired concentration of $100 \mu \mathrm{g} / \mathrm{ml}$ and injected in the established method. All the stressed samples are quantified for cefdinir [16].

\section{RESULTS}

\section{Chromatograms depicting the method development of cefdinir}

The chromatogram (fig. 1) obtained for method 1 was found to be more tailing factor. So, another set of trials were performed for reducing the tailing factor. The chromatogram (fig. 2) attained for method 2 was found to be a good peak shape but it was shown more retention time. Accordingly, further trials were performed by altering the mobile phase composition. The chromatogram (fig. 3) accessed for method 3 was found to be more retention time and it was not properly separated. Similarly, the chromatogram (fig. 4) gathered for method 4 was established to be consisting with an extra peak. Finally, the chromatogram (fig. 5) for method 5 was found to be a perfectly eluted peak with excellent peak shape. The tailing factor and retention time were observed within the limits. Therefore the mobile phase ratio was fixed at 60:40 (buffer: solvent).



Fig. 1: UPLC chromatogram for method 1.

\section{System suitability criteria}

A system suitability test was well defined based on the results found in several representative chromatograms. The column efficiency was determined from the analyte peak, the tailing factor was $<2.0$ and RSD for six replicate injection of system suitability solution were $<5.0 \%$. All the system suitability criteria's during validation of the study and batch analysis study were within the acceptance limit. The results of system suitability are depicted in table 1. 


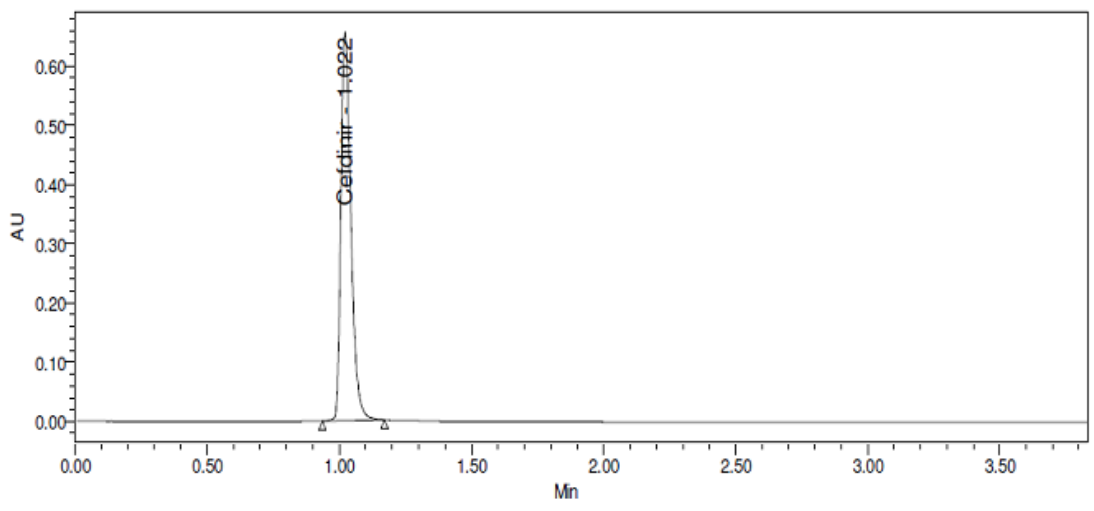

Fig. 2: UPLC chromatogram for method 2

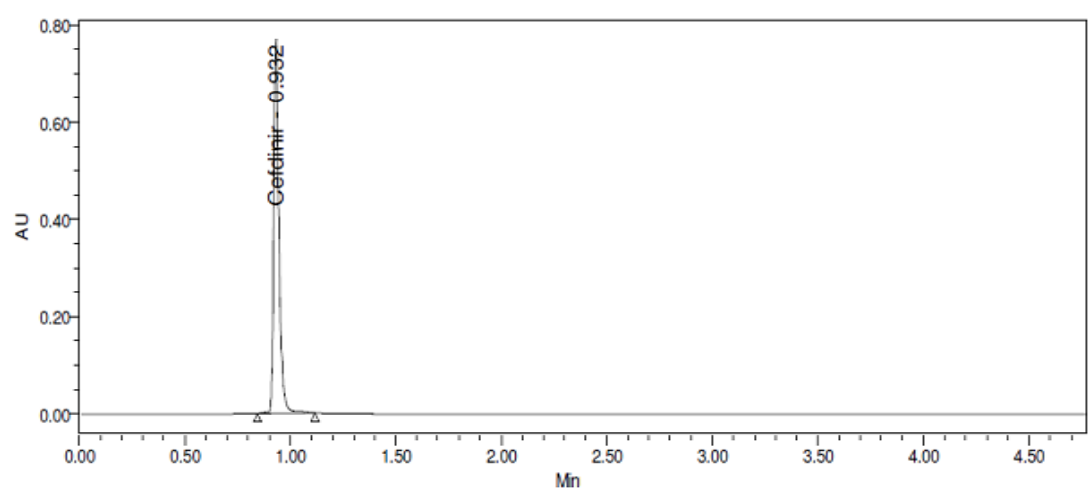

Fig. 3: UPLC chromatogram for method 3



Fig. 4: UPLC chromatogram for method 4

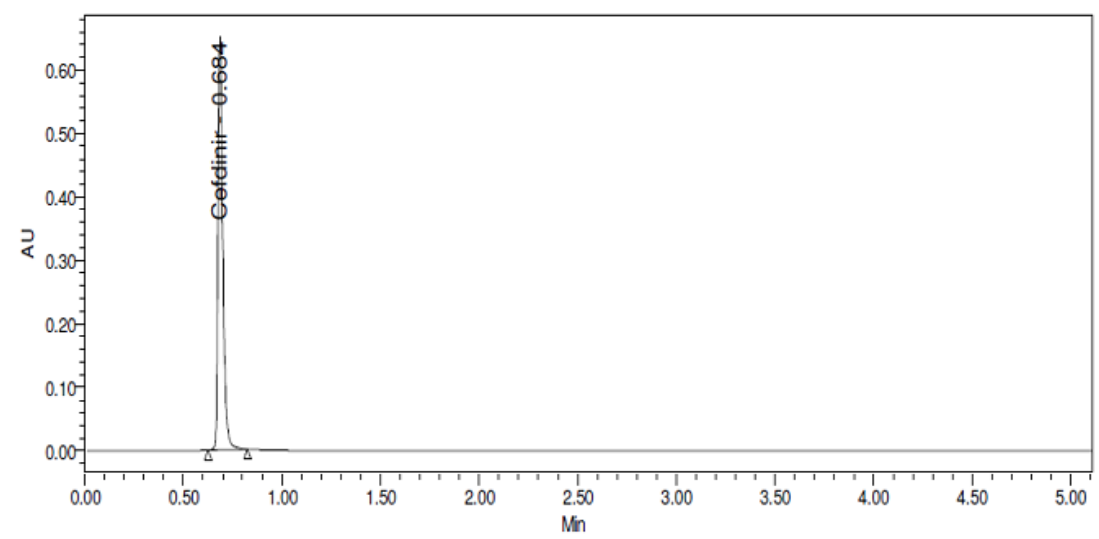

Fig. 5: UPLC chromatogram for method 5 
Table 1: System suitability data of cefdinir

\begin{tabular}{ll}
\hline Peak name & Cefdinir \\
\hline RT & 0.681 \\
Area(mean) & 1040275 \\
USP plate count & 4085 \\
USP tailing & 1.5 \\
Standard Deviation & 13158.9 \\
\%RSD & 1.3 \\
\hline
\end{tabular}

\section{Analytical method validation}

\section{Linearity}

The UPLC chromatogram data for determination of linearity was mentioned in table 2. The linearity of the optimized method was determined for six concentrations and the correlation coefficient was found to be 0.9993 for cefdinir. It showed that the developed method followed Beer-Lambert's law within the range of 25$150 \mu \mathrm{g} / \mathrm{ml}$.

\section{LOD and LOQ}

The limits of detection and quantification values were found to be 0.17 and $0.51 \mu \mathrm{g} / \mathrm{ml}$. Chromatograms of LOD and LOQ were shown in fig 6 and7, respectively.

Table 2: linearity data of cefdinir

\begin{tabular}{lll}
\hline Linearity level (\%) & Concentration (ppm) & \\
\hline 0 & 0 & Area \\
25 & 25 & 269751 \\
50 & 50 & 538538 \\
75 & 75 & 782019 \\
100 & 100 & 1030526 \\
125 & 125 & 1314152 \\
150 & 150 & 1541214 \\
\hline
\end{tabular}

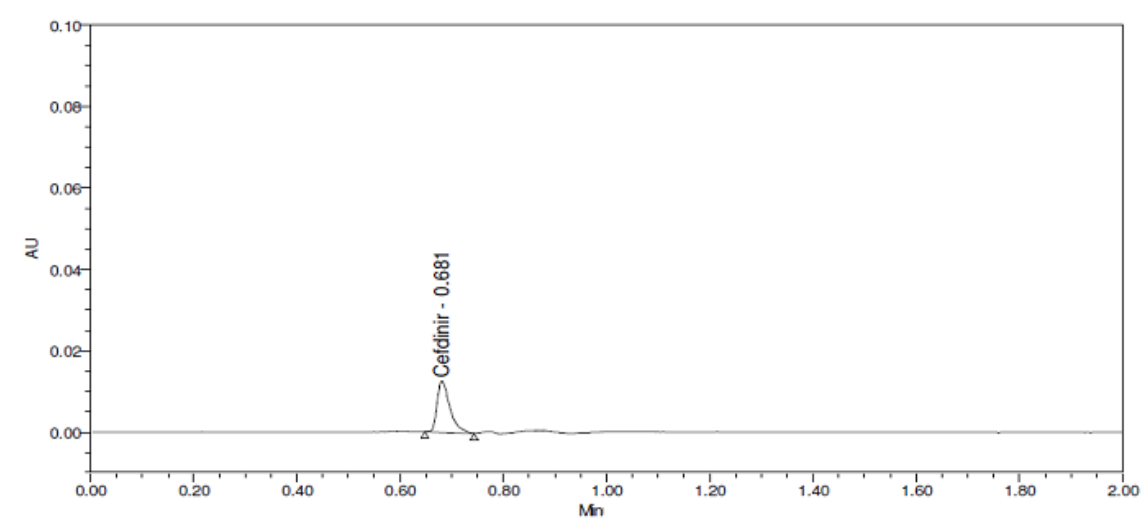

Fig. 6: LOD chromatogram of cefdinir



Fig. 7: LOQ chromatogram of Cefdinir 


\section{Precision}

The UPLC chromatogram data for inter-day precision and intraday precision were shown in table 3 and table 4 , respectively. The data for inter-day precision revealed that the \% RSD from six replicate injections of the sample solution was $0.8 \%$ which was within the limits specified (\% RSD NMT 2.0\%). Chromatogram data for intraday precision revealed that \% RSD for six replicate injections of the sample solution was found to be $0.9 \%$ which was within the limits specified (\% RSD NMT $2.0 \%$ ).

Table 3: Interday precision data of cefdinir

\begin{tabular}{ll}
\hline S. No. & Peak area \\
\hline 1 & 1039361 \\
2 & 1044609 \\
3 & 1043956 \\
4 & 1028539 \\
5 & 1026921 \\
Average & 1029440 \\
Standard Deviation & 1035471 \\
\% RSD & 8101.3 \\
\hline
\end{tabular}

Table 4: Intraday precision data of cefdinir

\begin{tabular}{ll}
\hline S. No. & Peak area \\
\hline 1 & 1045553 \\
2 & 1029005 \\
3 & 1047426 \\
4 & 1028097 \\
5 & 1026690 \\
6 & 1027574 \\
Average & 1034057 \\
Standard Deviation & 9676.9 \\
\hline
\end{tabular}

\section{Accuracy}

The accuracy of the method was evaluated in triplicate at the concentration levels like 50,100, and $150 \%$ of the target test concentration. The percentage of the recovery was calculated and obtained ranged from $98 \%$ to $102 \%$. Data was represented in table 5 .

\section{Robustness}

The UPLC chromatogram data for determining the robustness of the method was shown in table 6 . The data revealed that \% RSD for decrease and increase in flow rate for cefdinir were 1.2 and 0.8 , respectively which were within the limits specified (\% RSD NMT $2.0 \%$ ). The $\%$ RSD for mobile phase ratios of the drug was 1.0 and
1.3, respectively which were within the limits specified (\% RSD NMT 2.0\%). The percentage RSD for decrease and increase in column oven temperature were 0.9 and 0.3 , respectively which were within the limits specified (\% RSD NMT 2.0\%). From the above study, it can be proven that the flow rate, mobile phase ratio and column oven temperature were robust in the allowable variations.

\section{Specificity}

The forced degradation study by using UPLC revealed that the drug was degraded under the influence of acid, alkali and hydrogen peroxide solution, thermal and photolytic conditions. Data was recorded in table 7.

Table 5: Accuracy data of cefdinir

\begin{tabular}{llll}
\hline \% level & Amount spiked $(\boldsymbol{\mu g} / \mathbf{m l})$ & \% recovery & Mean \% recovery \\
\hline $50 \%$ & 50 & 99.73 & \\
& 50 & 98.91 & \\
$100 \%$ & 50 & 98.17 & \\
& 100 & 100.01 & \\
$150 \%$ & 100 & 99.59 \\
& 100 & 98.64 \\
& 150 & 100.70 \\
\hline
\end{tabular}

Table 6: Robustness data of cefdinir

\begin{tabular}{lll}
\hline S. No. & Parameter & \% RSD \\
\hline 1 & Flow Minus & 1.2 \\
2 & Flow Plus & 0.8 \\
3 & Mobile phase Minus & 1.0 \\
4 & Mobile phase Plus & 1.3 \\
5 & Temperature minus & 0.9 \\
6 & Temperature plus & 0.3 \\
\hline
\end{tabular}


Table 7: Degradation data of cefdinir

\begin{tabular}{lll}
\hline S. No. & Degradation condition & \% drug degraded \\
\hline 1 & Acid & 3.95 \\
2 & Alkali & 2.46 \\
3 & Oxidation & 1.58 \\
4 & Thermal & 1.11 \\
5 & UV & 1.05 \\
6 & Water & 0.64 \\
\hline
\end{tabular}

\section{DISCUSSION}

Validation of the developed method was done as per ICH guidelines. The method was found to be specific, stability indicating. This method exhibited an excellent performance in terms of sensitivity and speed. Satisfactory results were obtained from validation of the method. The correlation coefficient was found to be greater than 0.98 which was within the limits specified (NLT 0.99). Hence, the results shown that an excellent correlation existed between the peak area and concentration of the analyte. The high value of the correlation coefficient showed good linearity. The standard addition and recovery experiments were conducted to demonstrate the accuracy of the method. The recovery was found to be in the range of $98-102 \%$. High recovery results obtained from the proposed UPLC assay method indicates that this method can be used for quantitative routine quality control analysis of pharmaceutical dosage forms. The precision of a method determines the closeness of agreement between a series of measurements of the same sample. The $\%$ RSD values were found to be 0.8 and $0.9 \mu \mathrm{g} / \mathrm{ml}$. These values were well within the generally acceptable limit of $<2 \%$. Hence, confirming the good precision of the assay method. The limit of detection (LOD) of a compound is defined as the lowest concentration that can be detected. The limit of quantification (LOQ) is the lowest concentration of a compound that can be quantified. The sensitivity of the method was measured by calculating the limit of detection and limit of quantification [17]. It was observed that the LOD was $0.15 \mu \mathrm{g} / \mathrm{ml}$ and LOQ was $0.51 \mu \mathrm{g} / \mathrm{ml}$. It was particularly important to note that the injection volume used in this method was only $1.0 \mu$ l. Therefore, the minimum amount of analyte that can be quantified in a single injection was low. This proves the sensitivity of the method and its effectiveness. The ability of this method to separate and accurately measure the peak of interest indicates the specificity of the method [18]. The robustness of an analytical procedure is the measure of its ability to remain unaffected by small, but deliberate, variations in method parameters and provides sign of its reliability during normal usage. In all the deliberate varied chromatographic conditions the tailing factor of cefdinir was less than 2.0. There was a very slight variation in the resolution and tailing factor results observed in all the robustness conditions illustrating the robustness of the method. The peak purity test results derived from UV detector confirmed that the cefdinir peaks were pure and homogeneous in all the analyzed stressed conditions. This shows that the method is specific and stability indicating. Purity angle for the selected drug components in all stress conditions was found to be less than the threshold angle.

\section{CONCLUSION}

A new sensitive, simple, rapid, suitable, precise, accurate and stability indicating RP-UPLC method coupled with UV detector has been developed. The developed method was completely validated with respect to specificity, system suitability, linearity, limit of detection and quantification, accuracy, precision and robustness. The result of validation showed satisfactory data for all the parameters tested.

\section{ACKNOWLEDGEMENT}

The authors are thankful to the management of GITAM University, Visakhapatnam, Andhra Pradesh, India, for providing necessary facilities to carry out the research work.

\section{AUTHORS CONTRIBUTION}

The complete research work was suggested and designed by Raja Sundararajan. Method development and validation works were carried out by Krishnaphanisri Ponnekanti. Further, the manuscript was drafted by Krishnaphanisri Ponnekanti and it was edited by Raja Sundararajan. Authors read and approved the final manuscript.

\section{CONFLICT OF INTERESTS}

\section{Authors declare no conflict of interest}

\section{REFERENCES}

1. Peter M, Ladislav N. On the importance of pharmaceutical analysis. Res Rev J Pharm Anal 2015;4:13-4.

2. Himanshu Gupta, Aqil M, Khar RK, Ali A, Sharma A, Prakash C. Development and validation of a stability-indicating RP-UPLC method for the quantitative analysis of sparfloxacin. J Chromatogr Sci 2014; 7:135-40.

3. Ram G, Navneet Singh, Srinivas KS, Binayak D, Ahmed A. UPLC method development and validation for cefditoren pivoxil in the active pharmaceutical ingredient. J Appl Pharm Sci 2011;1:149-53.

4. Raja Abhilash P, Venkateshwar Rao J. Development and validation of a new RP-UPLC method for the quantitative determination of olanzapine in tablet dosage form. Asian J Pharm Clin Res 2013;6:178-81.

5. Malleswararao CSN, Suryanarayana MV, Mukkanti K. Simultaneous determination of sitagliptin phosphate monohydrate and metformin hydrochloride in tablets by a validated UPLC method. Sci Pharm 2012;80:139-52.

6. Antil P, Kaushik D, Jain G, Srinivas KS, Indu Thakur. UPLC method for simultaneous determination of valsartan and hydrochlorothiazide in drug products. J Chromatogr Sep Tech 2013;4:1-5.

7. Kishore G, Kamala Babu B, Guru Charana Das V. RP-HPLC method for the estimation of ceftriaxone and cefdinir thirdgeneration cephalosporin in the dosage form. Int J Mod Chem Appl Sci 2016;3:392-7.

8. Hasheem H, GoudS AA, Hassan W. Development and validation of a rapid stability indicating the chromatographic determination of Cefdinir in bulk powder and dosage form using monolithic stationary phase. J Liq Chromatogr Relat Technol 2013;36:2292-306.

9. Shahed GM, Ashik U, Maruf A Al, Ahmed MU, Mohammad SI, Nahar Z, et al. a Simple RP-HPLC method for the determination of cefdinir in human serum: validation and application in a pharmacokinetic study with a healthy bangladeshi male volunteer. J Pharm Sci 2011;10:109-16.

10. Shah PB, Pundarikakshudu K. Difference spectroscopic and reverse phase HPLC methods for the estimation of cefdinir in pharmaceutical dosage forms. Indian J Pharm Sci 2006;68:90-3.

11. Rajeev J, Keisham R, Nimisha J. Electrochemical evaluation and determination of cefdinir in dosage form and biological fluid at mercury electrode. J Electrochem Soc 2007;154:199-204.

12. Khan A, Iqbal Z, Khan MI, Javed K, Khan A, Ahmad L, et al. Simultaneous determination of cefdinir and cefixime in human plasma by RP-HPLC/UV detection method: method development, optimization, validation, and its application to a pharmacokinetic study. J Chromatogr B 2011;879:2423-9.

13. Chen ZJ, Zhang J, Yu JC, Cao GY, Wu XJ, Shi YG. A selective method for the determination of Cefdinir in human plasma using liquid chromatography electrospray ionization tandem mass spectrometry. J Chromatogr B 2006;834:163-9.

14. Abdel-Aziz O, Farouk M, Nagi R, Abdel-Fattah L. Simple spectrophotometric and HPTLC-densitometric methods for determination of cefdinir in bulk powder and pharmaceuticals and in presence of its hydrolytic degradation products. J Appl Pharm Sci 2014;4:129-36. 
15. Balaji N, Sivaraman VR, Neeraja P. A validated uplc method for the determination of process-related impurities in the antimigraine bulk drug. J Appl Chem 2013;3:20-8.

16. Yanamandra R, Vadla CS, Puppala UM, Patro B, Murthy YLN, Parimi AR. Development and validation of a rapid RP-UPLC method for the simultaneous estimation of bambuterol hydrochloride and montelukast sodium from tablets. Indian J Pharm Sci 2012;74:116-21.
17. Shashikant B, Landge, Sanjay A, Jadhav, Shrihari P, Vishwambar, et al. Development and validation of an RP-UPLC method for the determination of iloperidone, its related compounds and degradation products in bulk and dosage form. Am J Anal Chem 2014;5:969-81.

18. Richard T, Kenneth D, Ruhi U, Joel S, Blake WE. Development and validation of a UPLC method for rapid and simultaneous analysis of proton pump inhibitors. Pharm Sci-Tech 2015;16:30-4. 